\title{
Kulturelle Selbstbeschreibung
}


Simone Imhof

\section{Kulturelle \\ Selbstbeschreibung}

Bildungsperspektiven eines

Spannungsverhältnisses

黑 Springer VS 
Simone Imhof

Nürnberg, Deutschland

Dissertation an der Universität Würzburg, Fachbereich Pädagogik, 2015

ISBN 978-3-658-11893-8

ISBN 978-3-658-11894-5 (eBook)

DOI 10.1007/978-3-658-11894-5

Die Deutsche Nationalbibliothek verzeichnet diese Publikation in der Deutschen Nationalbibliografie; detaillierte bibliografische Daten sind im Internet über http://dnb.d-nb.de abrufbar.

\section{Springer VS}

(C) Springer Fachmedien Wiesbaden 2016

Das Werk einschließlich aller seiner Teile ist urheberrechtlich geschützt. Jede Verwertung, die nicht ausdrücklich vom Urheberrechtsgesetz zugelassen ist, bedarf der vorherigen Zustimmung des Verlags. Das gilt insbesondere für Vervielfältigungen, Bearbeitungen, Übersetzungen, Mikroverfilmungen und die Einspeicherung und Verarbeitung in elektronischen Systemen.

Die Wiedergabe von Gebrauchsnamen, Handelsnamen, Warenbezeichnungen usw. in diesem Werk berechtigt auch ohne besondere Kennzeichnung nicht zu der Annahme, dass solche Namen im Sinne der Warenzeichen- und Markenschutz-Gesetzgebung als frei zu betrachten wären und daher von jedermann benutzt werden dürften.

Der Verlag, die Autoren und die Herausgeber gehen davon aus, dass die Angaben und Informationen in diesem Werk zum Zeitpunkt der Veröffentlichung vollständig und korrekt sind. Weder der Verlag noch die Autoren oder die Herausgeber übernehmen, ausdrücklich oder implizit, Gewähr für den Inhalt des Werkes, etwaige Fehler oder Äußerungen.

Gedruckt auf säurefreiem und chlorfrei gebleichtem Papier

Springer Fachmedien Wiesbaden ist Teil der Fachverlagsgruppe Springer Science+Business Media (www.springer.com) 


\section{Danksagung}

Die Promotion ist aus zahlreichen Gesprächen und einer am Lehrstuhl bestehenden Vorliebe für bildungsphilosophische Texte entstanden. Ich möchte mich deshalb zunächst bei meinen beiden Gutachtern Prof. Dr. A. Dörpinghaus und Prof. Dr. H.-J. Petsch für die Betreuung der Forschungsarbeit bedanken. Herr Prof. Dr. Dörpinghaus hat mir den für ein solches Projekt notwendigen Freiraum gewährt und mich durch seine Kritik und seine wertvollen Anregungen im Fortgang der Arbeit geduldig, freundlich, aber bestimmt, und vertrauensvoll unterstützt. Auch meinen Kolleginnen und Kollegen am Lehrstuhl, besonders Maren Schüll, sei an dieser Stelle für ihre fachlichen Hinweise und für ihre kollegiale sowie freundschaftliche Begleitung gedankt. Und schließlich gilt es ein Dankeschön an die Hilfskräfte des Lehrstuhls sowie Tante und Onkel zu richten, die mir bzgl. der formalen Gestaltung weiterhalfen.

Dieses Projekt hätte jedoch niemals stattfinden können, wenn es nicht im familiären Umfeld auf so großartige Unterstützung hätte zählen können, die sich in vielerlei Hinsicht über all die Jahre zeigte: Ich möchte mich für die beständige Ermutigung und Aufmunterung meines Mannes sowie die Geduld meiner beiden Kinder bedanken. Weiterhin bin ich dankbar für die vielen Stunden, in denen sich meine Oma und besonders meine Eltern so liebevoll um die Kinder sorgten, um mir einen Freiraum für Lese- und Schreibphasen zu verschaffen.

Nürnberg, im Juni 2015

Simone Imhof 


\section{Inhaltsverzeichnis}

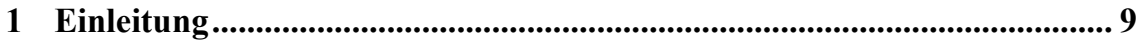

1.1 Der Problemhorizont kultureller Selbstbeschreibung............................ 12

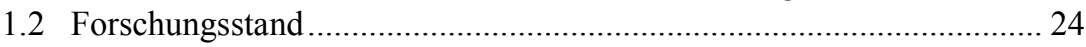

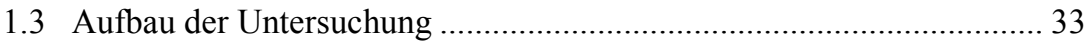

2 Zur Konstruktion des symbolischen Raumes bei E. Cassirer .................. 37

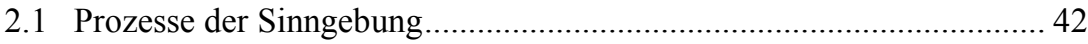

2.1.1 Symbolisierung und Menschsein 45

2.1.2 Das Symbol in seiner Funktion der Repräsentation von Wirklichkeit............................................................................ 51

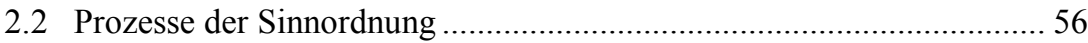

2.2.1 Von der anschaulichen Gestalt zur symbolischen Struktur ....... 57

2.2.2 Bewegungen und Veränderungen im Raum .............................. 62

2.3 Kulturelle Selbstbeschreibung aus raumtheoretischer Perspektive erste Annäherung ....................................................................... 73

3 Anfänge einer Dekonstruktion des symbolischen Raumes bei

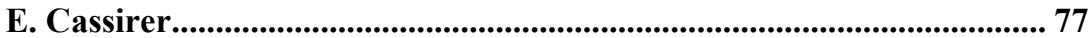

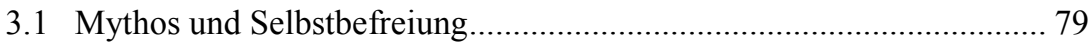

3.1.1 Im Geflecht symbolischer Formen ........................................ 83

3.1.2 Die Konstitution des symbolischen Raumes im Mythos ........... 89

3.2 Mythos, Macht und Autonomie.......................................................... 96

3.3 Kulturelle Selbstbeschreibung aus raumtheoretischer Perspektive -

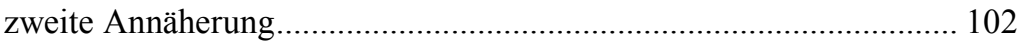

4 Über eine Polarisierung von Verortung und symbolischem Raum ...... 109

4.1 Zur Unterscheidung von Raum, Ort und Verortung............................ 111

4.1.1 Die Einheit von Wissen und Handeln...................................... 115

4.1.2 Das Imaginäre, Symbolische und Reale ................................. 120

4.2 Gründe und Formen der Verortung ……........................................... 124

4.2.1 Symbolische Mitgliedschaft und die Imagination des Selbst .. 128

4.2.2 Nähe-Distanz-Verhältnisse als Ordnung des Selbst ................ 136 
4.3 Kulturelle Selbstbeschreibung aus raumtheoretischer Perspektive dritte Annäherung

5 Zwischenräume:

Über das Ineinander von Verortung und symbolischem Raum............ 147

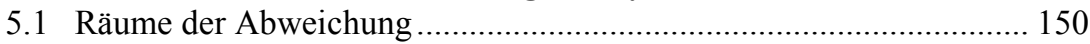

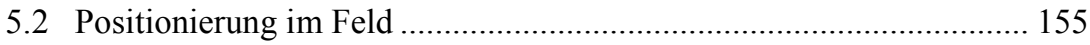

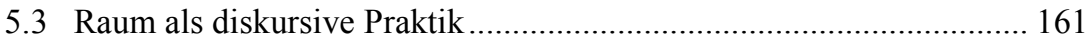

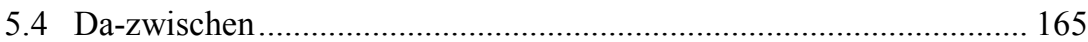

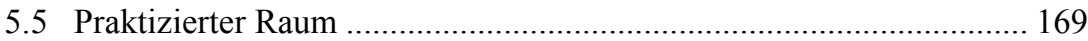

5.6 Kulturelle Selbstbeschreibung aus raumtheoretischer Perspektive -

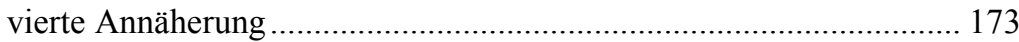

6 Bildungsperspektiven eines Spannungsverhältnisses..................................... 179

6.1 Implikationen eines raumtheoretischen Zugangs ............................... 183

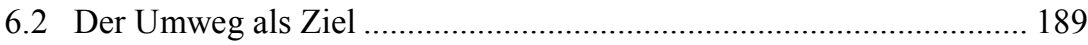

7 Schlussüberlegungen und systematische Erwägungen ........................... 199

8 Siglenverzeichnis ............................................................................................... 211

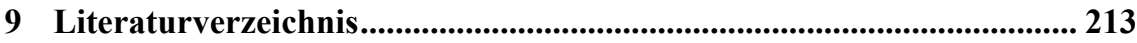

